\title{
SAIR PARA BUSCAR, ENCONTRAR E VOLTAR: DE COMO SURGIU UMA IGREJA DO SANTO DAIME NO URUGUAI
}

Juan Scuro ${ }^{1}$

Resumo: $\mathrm{O}$ artigo constrói uma narrativa em torno do processo de fundação de uma igreja do Santo Daime no Uruguai. Presente há mais de quinze anos, Céu de Luz é uma igreja uruguaia pertencente à ICEFLU, linha expansionista da religião Santo Daime. A década de 1990 forma o quadro temporal de um grande processo de transnacionalização desta religião ayahuasqueira brasileira fundada por Raimundo Irineu Serra nas primeiras décadas do século passado. A mesma década de 1990 marca a chegada, no Uruguai, desta religião, proveniente do Amazonas. O texto dá especial atenção à trajetória do fundador e dirigente da igreja uruguaia, Ernesto Singer, esboçando os desdobramentos próprios ao processo de transnacionalização religiosa.

Palavras-chave: Santo Daime; Uruguai; Ayahuasca; Transnacionalização religiosa; Trajetória.

Abstract: The article constructs a narrative around the foundation of a Santo Daime church in Uruguay. Been present for over fifteen years, Céu de Luz is an Uruguayan daimista church belongs to ICEFLU, expansionist line of the Santo Daime religion. The 1990 is the timeframe of a major process of transnationalization of this Brazilian Ayahuasca religion founded by Raimundo Irineu Serra in the early decades of last century. The same 1990 marks the arrival, in this case to Uruguay, of this Amazonian religion. The text gives special attention to the trajectory of the church founder and leader of Céu de Luz, Ernesto Singer, outlining the consequences of the transnationalization process.

Keywords: Santo Daime; Uruguay; Ayahuasca; Religious transnationalization; Trajectory.

${ }^{1}$ Doutorando pelo Programa de Pós-Graduação em Antropologia Social, UFRGS. 


\section{INTRODUÇÃO}

Este artigo trata do surgimento da igreja daimista Céu de Luz, em Montevidéu, fundada por Ernesto Singer na década de 1990. O presente texto faz parte, readaptado aos efeitos desta comunicação, de um dos capítulos da minha dissertação (Scuro, 2012) que privilegiou um olhar "mais de perto" sobre o processo de transnacionalização do Santo Daime para o Uruguai. O conjunto deste artigo pretende mostrar uma forma de nos aproximarmos do processo de surgimento de uma narrativa religiosa como o Santo Daime, mediante um processo de transnacionalização, na especificidade do Uruguai.

Aqui relata-se, elaborando as narrativas - e trajetória - de Ernesto Singer e de outros daimistas, o processo de fundação desta igreja e quais os desdobramentos que estão se evidenciando. $\mathrm{O}$ artigo privilegia - explicitamente - narrar esta historia com o objetivo de "mostrar", etnograficamente, um processo concreto de transnacionalização e fundação de uma instituição religiosa.

\section{A PRESENÇA DO SANTO DAIME NO URUGUAI}

A existência de Céu de Luz no Uruguai está muito relacionada à trajetória do seu atual dirigente, Ernesto Singer. Porém, o processo de formação de uma igreja não depende, claro, de uma única pessoa. Assim como Ernesto, vários outros descobriam mundos de sentidos possíveis como saídas para outras formas de vivenciar o religioso. Ao mesmo tempo em que, como veremos, Ernesto procurava, para sua própria vida, novas formas de expressar suas inquietações - fugindo do modelo proposto por igrejas tradicionais -, outras trajetórias levavam indivíduos em busca de experiências espirituais convergirem no universo de sentidos produzido pelo Santo Daime.

A igreja Céu de Luz (Centro de Iluminación Cristiana José Gonçalves), dirigida por Ernesto, é a única igreja uruguaia pertencente doutrinariamente à linha expansionista do Santo Daime, fundada pelo Padrinho Sebastiāo em 1974, denominada Centro Eclético de Fluente Luz Universal Raimundo Irineu Serra (CEFLURIS). Como colocado acima, a presença da igreja Céu de Luz no Uruguai está ligada à trajetória da vida de Ernesto, pois foi ele um dos primeiros a levar a público o Santo Daime a outras pessoas no 
Uruguai. Junto com alguns poucos amigos, com os quais compartilhou a experiência de beber Santo Daime, Ernesto começou a construir o que hoje em dia é a igreja Céu de Luz. Trazer essa trajetória, que dá origem à igreja, requereria que nos deslocássemos para o Rio de Janeiro e o Amazonas, lugares de grande relevância na vida de Ernesto e de Céu de Luz. Outras cidades mais ao sul do Brasil, como Florianópolis e Porto Alegre, também ocupam um lugar destacado na vida da igreja. Nos últimos anos, a cidade Rivera-Santana do Livramento, na fronteira entre o Uruguai e o Brasil, virou sede da mais nova igreja daimista constituída na região que mantém algum tipo de laço com Céu de Luz.

O estado brasileiro do Rio Grande do Sul e, mais especificamente, a cidade de Porto Alegre, tem ocupado um papel importante nos processos de expansão de manifestaçóes religiosas que, provenientes do Brasil, chegam ao território uruguaio. A proximidade geográfica entre as regiōes do Rio Grande do Sul e do Uruguai faz deste último país uma "fronteira permeável" (Pi Hugarte, 1993) aos processos de expansão religiosa, principalmente do segmento afro-brasileiro (Oro, 1999).

No caso do Santo Daime no Uruguai, a relação com Porto Alegre é estabelecida posteriormente à fundação da igreja. Os primeiros anos da igreja do Santo Daime e do campo ayahuasqueiro uruguaio, em geral, devem mais a outras regiões ou cidades do que a Porto Alegre. Na gênese do Santo Daime no Uruguai, foram mais determinantes cidades como Florianópolis ou Rio de Janeiro, sendo que a capital gaúcha ocupa um lugar importante para Céu de Luz a partir da última década.

As relações com as comunidades daimistas CHAVE de São Pedro, em Porto Alegre, e Céu do Patriarca, em Florianópolis, são importantes, atualmente, em alguns aspectos da vida da igreja, principalmente no que refere à circulação do sacramento, o Santo Daime ou ayahuasca. Essas relações com Porto Alegre, mais especificamente, com Wilton Souza, começaram no ano 2000, quando, por ocasião da visita do Padrinho Alfredo² a Porto Alegre, Ernesto e Wilton (dirigente da igreja CHAVE de São Pedro em Porto Alegre)

\footnotetext{
${ }^{2}$ Atual autoridade máxima da Igreja do Santo Daime, o Padrinho Alfredo, mora na sede matriz, Céu do Mapiá, no estado do Amazonas.
} 
entraram em contato para ver a possibilidade de o Padrinho Alfredo visitar Montevidéu. Naquela ocasiāo, Ernesto viajou a Porto Alegre e participou de um trabalho junto com Wilton na comunidade Céu de São Miguel ${ }^{3}$, no município de Sapiranga, no Rio Grande do Sul.

Outras iniciativas, além das viagens de Ernesto, também ajudaram ao gradual conhecimento e experimentação com a ayahuasca nos primeiros anos da década de 1990 no Uruguai. O fluxo contínuo de uruguaios que visitam Florianópolis propicia o estabelecimento de vínculos com o Brasil por parte de um determinado conjunto da população uruguaia, que também facilitou a "descoberta" dos usos de ayahuasca.

Várias vias de conhecimento da ayahuasca estavam se formando no Uruguai ao longo da década de 1990, começando a criar o que hoje em dia, identificamos como um campo ayahuasqueiro uruguaio (Scuro, 2012). Assim, o Santo Daime, enquanto religião institucionalizada, não foi a única forma pela qual os uruguaios conheceram a ayahuasca; é, sim, a presença no Uruguai de uma igreja que pertence às denominadas religiões ayahuasqueiras brasileiras (Labate, 2004), uma das formas de uso ritual da bebida.

Vemos que, intrínseco à própria existência deste campo ayahuasqueiro uruguaio, é o fato do seu processo de transnacionalização. Seguindo a proposta de Stefania Capone (2010) de ver os processos de transnacionalização como sendo principalmente possíveis através do desenvolvimento de redes sociais que escapam à institucionalidade do Estado, propomos que conti-

\footnotetext{
3 A fundação da comunidade Céu de São Miguel, em 1998, pelo Padrinho Francisco "Chico" Corrente, foi o resultado da união de três pontos daimistas da região que existiam desde alguns anos (Greganich, 2010). Na mesma época da criação dos pontos que deram origem à Comunidade Céu de São Miguel, estavam se realizando os primeiros trabalhos com Santo Daime no Uruguai, por ocasiāo das eventuais visitas de Ernesto ao país durante os anos em que morou entre Céu do Mar, no Rio de Janeiro, e Céu do Mapiá, no Amazonas.

O Padrinho Chico Corrente foi preso na Espanha, no ano 2000, por ter querido ingressar naquele país com 10 litros de ayahuasca. Foi liberado depois de alguns dias de prisão. Recentemente, em dezembro de 2011, ele passou pela região de Porto Alegre, visitando a igreja CHAVE de São Pedro (dirigida por Wilton) e outras. Posteriormente, ficou alguns dias em Montevidéu visitando a comunidade Céu de Luz, poucos dias antes de falecer, em janeiro de 2012. Não foi a primeira vez que Chico Corrente visitava Montevidéu.
} 
nuemos privilegiando a construção narrativa de uma trajetória específica que, entre outras coisas, permite o surgimento de uma instituição religiosa. Se são esses permanentes cruzamentos de fronteiras por parte de indivíduos organizados o que tornam possíveis os processos de transnacionalização (Capone, 2010), vejamos então uma das especificidades do processo de transnacionalização do Santo Daime para o Uruguai.

\section{O SURGIMENTO DA IGREJA CÉU DE LUZ}

O ano de 1991 marca um momento importante na gênese do que atualmente é uma igreja do Santo Daime no Uruguai, registrada como associação civil, no Ministério de Educação e Cultura, sob o nome "Centro de Iluminación Cristiana José Gonçalves” e reconhecida pelo CEFLURIS, desde 2006, como igreja pertencente a essa linha fundada pelo Padrinho Sebastião em 1974, depois da morte do Mestre Irineu, em 1971. É com o surgimento dessa linha que o Santo Daime passaria por um processo de expansão permanente, muito especialmente a partir da atual presidência do Padrinho Alfredo, iniciada em 1990.

Voltemos para o Uruguai. Foi naquele ano de 1991 que um primeiro ritual feito entre três pessoas e dirigido por Ernesto trazia a público as primeiras notícias sobre a doutrina do Santo Daime e sobre os usos daquela bebida, que o próprio Ernesto tinha levado para o Uruguai, naquela ocasião, em um frasco. Ele tinha saído do Uruguai em 1988 e passado vários anos morando entre a comunidade daimista Céu do Mar, no Rio de Janeiro, e a matriz Céu do Mapiá, no Amazonas.

Aquele primeiro trabalho de 1991, realizado na casa de um dos participantes, em Solymar, ${ }^{4}$ despertaria o interesse de aquelas pessoas por continuar conhecendo e experimentando a bebida e a doutrina do Santo Daime.

Nesses primeiros anos da década de 1990, outras vias permitiam também o conhecimento e a experimentação com o Santo Daime. Em Florianópolis, começava a se formar uma incipiente comunidade daimista

\footnotetext{
${ }^{4}$ Cidade sobre a costa de Canelones, departamento limítrofe com Montevidéu.
} 
que, a partir de 1996, seria fundada como "Associação Ambientalista, Comunitária e Espiritualista Patriarca São José" (ACEPSJ). A relação de pessoas do entorno daquele primeiro trabalho feito em 1991 com Florianópolis foi uma ponte importante no incremento das relaçôes que, no Uruguai, começavam a dar forma à atual comunidade daimista uruguaia.

Quatro anos depois daquele primeiro e muito pequeno trabalho de 1991, Ernesto voltaria para o Uruguai, dessa vez com dois litros de Santo Daime. Nos trabalhos dirigidos por Ernesto, em 1995, já participavam cerca de dez pessoas, e os encontros continuavam sendo nas casas dos próprios participantes. No final de 1995, Ernesto estava novamente no Céu do Mapiá, no Amazonas. Tinha se iniciado um processo de conhecimento da doutrina por parte de várias pessoas. O Santo Daime já fazia sentido como via de expressão e aprendizado de uma fé depositada naquela bebida e nos seus usos no contexto criado por Ernesto ao dirigir os trabalhos. A continuidade daquilo que tinha sido iniciado anos antes estaria marcada pelo retorno do que, naquele momento, já era desejado por aqueles que tinham conhecido o universo daimista. Do Uruguai surgia a demanda cada vez maior daquilo que tinha começado a emergir como uma proposta efetiva.

\section{O PEDIDO DE RETORNO DA BEBIDA MILAGROSA E O HERÓI HUMILDE}

Fim de 1995, Céu do Mapiá, Amazonas. O aprendizado dos saberes da doutrina da floresta por parte de Ernesto estava produzindo um dirigente com o acúmulo de capital religioso necessário para levar à prática, no seu próprio país, aquele universo de sentido que ele estava alcançando. $\mathrm{O}$ pedido de retorno de quem tinha se "retirado do mundo" se formalizaria por meio de um daqueles que, tendo tido uma aproximação do Santo Daime nas primeiras experiências no Uruguai, estava precisando de mais.

Ernesto recebeu notícias de Ruben, um dos amigos que participara dos primeiros trabalhos no Uruguai. Já eram vários os que queriam continuar praticando aqueles encontros junto com ele. Ao pedido de retorno de Ernesto para o Uruguai para realizar mais encontros e dar continuidade àquilo que 
tinha começado, incrementava-se o estado de saúde do irmão de Ruben. Ele (Ruben) escreveu para Ernesto contando da situação do seu irmão, com a esperança de que o Santo Daime pudesse ajudar naquela situação; também falava da vontade de vários amigos de continuar realizando trabalhos. Eles estavam dispostos a arcar com as despesas necessárias para o retorno de Ernesto.

Naquele momento, Ernesto depositava em José Gonçalves (um feitor ${ }^{5}$ de Santo Daime de Céu do Mapiá, que depois acabaria sendo o patrono da igreja Céu de Luz) um carinho e uma fé muito grandes. Ernesto estava apreendendo muito com o $Z e ́$, como ele o chama, principalmente sobre a realização de feitios, prática na qual Gonçalves era especialista. José Gonçalves é uma pessoa do Daime há muito tempo, tendo transitado nas redondezas de Céu do Mapiá. De alguma forma, Zé tinha se transformado na referência de Ernesto nos anos da sua residência no Céu do Mapiá. Ernesto e Zé estabeleceram uma amizade muito grande.

Ao receber a notícia do Uruguai, sabendo da necessidade e da vontade que vários amigos tinham de continuar com os trabalhos, Ernesto sugeriu que José Gonçalves o acompanhasse no Uruguai. Contando com o apoio de Zé, a ida ao Uruguai seria mais eficaz, simbolicamente. Era a presença necessária para legitimar o que estava acontecendo, e dar início a um novo período no processo de afirmação do Santo Daime no Uruguai. Ernesto pediu, então, a companhia de José Gonçalves na sua volta para o Uruguai. Depois de um feitio que Zé tinha que fazer no Rio de Janeiro, no início de 1996, eles iriam juntos para o Uruguai. Assim o fizeram.

\section{DE ABRIL DE 1996}

José Gonçalves estava no Uruguai junto com Ernesto. Dessa vez levaram trinta litros de Santo Daime. No aeroporto, o pessoal de fiscalização revistou

\footnotetext{
${ }^{5}$ Pessoa encarregada de dirigir o processo de elaboração do Santo Daime. A qualidade de feitor é, dentro das tradições ayahuasqueiras, um elemento de distinção e acúmulo de capital religioso importante.
} 
seus pertences, mas, mesmo assim, conseguiram entrar com a bebida sem maiores dificuldades. Naqueles dias, reuniram-se com as pessoas que estavam querendo dar continuidade aos trabalhos e, finalmente, no fundo da casa do pai ${ }^{6}$ de Ernesto, em Carrasco ${ }^{7}$, realizaram o trabalho que marcaria a fundação da igreja. Aproveitando a presença de Zé Gonçalves, os fundadores da igreja realizaram mais alguns encontros em outros locais, completando vários trabalhos no período de um mês. Após a vinda de Ernesto e Zé do meio da floresta e dos ensinamentos transmitidos por eles, estavam dadas as condiçōes para começar a se pensar numa certa autonomia no Uruguai para continuar conhecendo e dando forma a uma comunidade daimista própria.

Tudo estava encaminhado para a construção de uma igreja: por um lado, estava se iniciando um momento de consolidação e crescimento, havia pessoas interessadas e Ernesto já detinha um alto domínio e conhecimento da doutrina. Por outro lado, era necessária a construção física de uma igreja que pudesse abrigar tudo aquilo que estava começando. Juan Singer, o pai de Ernesto, tinha naquele momento um terreno nas redondezas de Montevidéu, a vinte e quatro quilômetros do centro da cidade, lugar onde atualmente está construída a Igreja Céu de Luz e mais algumas casas, dando forma a uma pequena comunidade de residentes daimistas.

\section{A CONSTRUÇÃO DA IGREJA E O NOVO RETIRO}

A igreja está localizada na área metropolitana de Montevidéu, a 24 quilômetros do centro da cidade. Politicamente, o território da igreja corresponde ao departamento de Canelones, limítrofe com Montevidéu, na conurbação chamada de Ciudad de la Costa. A cidade de Montevidéu tem tido seu processo de expansão desenvolvido ao longo da orla marítima

\footnotetext{
${ }^{6}$ Juan Adolfo Singer, o pai de Ernesto, é um político pertencente ao Partido Colorado. Foi deputado substituto por esse partido entre os anos de 1963 e 1964. Depois, a partir de 1967 e até 2005, ocuparia a titularidade no Parlamento, com interrupção no período ditatorial, entre 1973 e 1985. Nos períodos legislativos anteriores e posteriores à ditadura (1972-1973 e 1985-1990), foi senador.
}

${ }^{7}$ Bairro residencial de Montevidéu. 
do Rio da Prata, atravessando a fronteira política da capital e urbanizando a região sul de Canelones. A igreja fica do lado norte da Ciudad de la Costa, numa área pouco urbanizada. O barulho dos aviōes que chegam e decolam do aeroporto faz parte da sonoridade do lugar.

Depois dos muitos trabalhos realizados, contando com a presença de Zé Gonçalves no princípio de 1996, em janeiro de 1997, depois de Ernesto ter conversado com o seu pai sobre o uso do terreno, começou a construção da igreja, do templo. Esta construção já constituía uma forma de despersonalização, de desdobramento da figura de Ernesto da própria autonomia da comunidade. Ao mesmo tempo, é claro, a construção da igreja não deixava de significar a consolidação de um dirigente, que vinha construindo a própria narrativa de fundação da comunidade que ia se formando em torno da sua figura e da prática conjunta de um ritual novo para muitos. O duplo processo de individualização e desdobramento da relação Ernesto-Igreja criaria as condições para o processo de formação de uma nova comunidade religiosa.

A igreja foi construída e um grupo de pessoas ia se constituindo em torno dela. Ernesto voltou para Céu do Mapiá e os primeiros membros ficaram dando forma ao que estava surgindo. Ernesto voltaria em 1998, ano no qual a igreja Céu de Luz já estava acompanhando o calendário ritual do CEFLURIS. O estabelecimento definitivo de Ernesto no Uruguai, em 1998, também implicava a necessidade de criar um mecanismo de obtenção de Santo Daime, pois ele não era, nem é, elaborado pela própria igreja uruguaia. Provavelmente, o clima uruguaio não seja o mais adequado para o cultivo das plantas necessárias para elaborar o Santo Daime. As relações com Rio de Janeiro permitiram criar um mecanismo de traslado do Daime desse estado brasileiro para o Uruguai. Céu de Luz começou a importar Santo Daime do Rio de Janeiro por via aérea. Criou-se, então, um mecanismo que permitia o envio do sacramento por encomenda, mas ele não duraria muito tempo, por causa dos custos da referida via de circulação.

No mesmo ano de 1998, começariam a ser realizados os trâmites de obtenção de uma personalidade jurídica junto ao Ministério da Educação e Cultura, finalmente obtida no ano de 2002. 


\section{PERSONAGENS, REDES, ENCONTROS}

No início do século XXI, a igreja Céu de Luz foi se consolidando em relação a aspectos burocráticos, com a obtenção da personalidade jurídica no Uruguai, em 2002, e com o reconhecimento por parte da Igreja do Culto Eclético de Fluente Luz Universal (ICEFLU), obtido em 2006. A formalização burocrática e o processo de reconhecimento da igreja, tanto dentro do Uruguai como organização social quanto pela própria estrutura burocrática da matriz do Santo Daime, possibilitaram, entre outras coisas, uma maior facilidade para estabelecer redes transnacionais e receber visitas de outros países e igrejas.

O "povo do Santo Daime", designação dos daimistas para referirem-se às pessoas que fazem parte da doutrina, está espalhado pelo mundo. Tal coletividade de igrejas e pontos encontra mecanismos de comunicação para fazer circular informaçôes relevantes a cada igreja e à comunidade em geral. Uma dessas informações tem a ver com as possibilidades de visitas de Padrinhos ou Madrinhas às diferentes igrejas. As visitas acontecem com frequência, sendo que a igreja receptora deve, em geral, pagar as despesas de deslocamento e oferecer hospedagem. Visitas como a do Padrinho Alfredo implicam, também, o pagamento de uma determinada quantia de dinheiro, contribuição para a sustentabilidade da Igreja. Receber uma visita mobiliza totalmente a comunidade de Céu de Luz. Assim aconteceu com a última visita de Francisco Chico Corrente ao Uruguai, em dezembro de 2011. Alguns dias antes circulavam correios eletrônicos entre os membros de Céu de Luz para notificar sobre os trabalhos que seriam feitos com a presença de Chico Corrente, solicitar a colaboração de todos para arrumar a igreja, frequentar aquele espaço para aproveitar os conhecimentos do visitante, ter tempo para conversar com ele, além de convidar a levar comidas e bebidas, coisas para compartilhar nos momentos em que seriam realizados trabalhos junto ao visitante. Geralmente, os visitantes permanecem hospedados no próprio espaço da igreja, da comunidade de Céu de Luz. Espaços dentro do terreno da comunidade (como a casa onde ficava a igreja anterior à atual) servem de hospedagem. 
As visitas na igreja Céu de Luz têm sido várias. O Padrinho Alfredo visitou a comunidade em duas oportunidades, no ano 2000 e em 2006. A primeira visita do Padrinho Alfredo, em 2000, faria com que Ernesto e Wilton (dirigente da igreja CHAVE de São Pedro, em Porto Alegre) se conhecessem. Naquela oportunidade, Ernesto entrou em contato com Wilton sabendo da presença do Padrinho Alfredo em Porto Alegre. Ernesto e Wilton conheceram-se num trabalho na igreja Céu de São Miguel, por ocasiāo da visita do Padrinho Alfredo. Aquele encontro marcaria o início de uma relação de parceria que se mantém até hoje.

Vimos trazendo alguns episódios da vida de Ernesto que fizeram dele o atual dirigente da igreja daimista Céu de Luz em Montevidéu. É o momento, então, de aproximarmo-nos mais um pouco da sua vida, numa tentativa de conhecer as motivaçóes que o levaram a sair do Uruguai em um momento da sua vida e a forma como atualmente ele conta essa história.

\section{ERNESTO}

O que Ernesto tinha, quando nos conhecemos, era pouco tempo. Requer-se bastante dele para dirigir uma igreja, ser pai de três crianças, esposo, filho, administrar uma estância, um estacionamento... Enfim, o cotidiano de Ernesto está bem cheio de atividades. Difícil ter tempo para deixar que uma pessoa apareça de repente pretendendo conhecer coisas de sua vida. Mas Ernesto possibilitou isso e, no meio de suas muitas atividades, permitiu a entrada na sua vida, na sua casa, na sua família e na sua igreja, do sujeito estranho que aparecia de repente e (talvez) não precisamente no melhor momento.

Uma figura alta e magra, serena, de voz baixa, barba de três dias e andar lento; como se nunca tivesse pressa, embora as atividades não parem. Pararam, sim (até certo ponto), por um tempo, de forma obrigada, depois de um acidente grave que sofreu ao cair do cavalo que montava. Ainda está se recuperando, devagar. Ernesto ficou vários dias sem poder se movimentar, mas isso não significou deixar de acompanhar os trabalhos na igreja, que dista alguns metros de sua casa. Depois de vinte e três anos tomando Santo 
Daime e de mais de quinze dirigindo trabalhos, Ernesto tomou com muita calma o fato de não poder dirigir os trabalhos seguintes ao seu acidente. Isso não significou deixar de acompanhar o que acontecia na igreja. Da janela do seu quarto, era possível ver a igreja, acompanhar os hinos e tomar o Santo Daime nos momentos que, na igreja, ocorriam os despachos de Daime.

As atividades de Ernesto são várias e deixam pouco tempo para estar em casa com tranquilidade durante a semana. Isso faz do final de semana um momento de encontro e de possibilidade de dedicar tempo aos filhos. Sebastián, o mais velho dos filhos de Ernesto e Alejandra, tem dez anos. Poucas vezes vi crianças de sua idade mantendo diálogos com adultos como faz Sebastián. A inteligência, criatividade, espontaneidade e energia de Sebastián chamam bastante a atenção. Gerónimo e Clara, mais novos, não são menos ativos e criativos. $\mathrm{O}$ espaço onde moram lhes permite brincar com tranquilidade, com espaço suficiente para desenvolver todas suas inquietudes. A igreja faz parte da sua paisagem, pois fica a poucos metros da casa. $\mathrm{Na}$ casa moram Ernesto, Alejandra, Sebastián, Gerónimo e Clara, mas, muito perto, a poucos metros, numa outra casa, mora Stella, a mãe de Ernesto.

Vejamos como Ernesto conta para quem se aproxima dele a sua própria história, o processo que o levou a "sair a buscar" e "encontrar":

Soy nieto de una generación de inmigrantes de los años 1920, 1930, las fechas que se vinieron los que fueron mis abuelos. De mis cuatro abuelos, solo mi abuela materna era nacida acá. Mis otros tres abuelos ya vinieron de Europa, cada uno de un país distinto. Tengo ancestros europeos en seis países distintos.

No tuve una formación específicamente muy religiosa, tuve, eso sí... Fui bautizado, hice catequesis y la primera comunión, pero no era, no soy de origen de una familia muy religiosa, ni en mi casa era una casa que se viviera mucho ninguna religión ni se hablara mucho del tema.

Mi padre no es muy practicante de ninguna religión y por el lado de mi madre tampoco. Yo viví con mi padre casado con una mujer que fue como la que en aquel tiempo insistió en que era importante que nos bautizáramos y que tomáramos la primera comunión. Y, bueno, el Santo Daime tiene muchos 
puntos de contacto con el catolicismo, o tienen... Se nutre, por un lado, de la religión católica. El fundador era de una familia católica, la madre era muy devota y, bueno, en el Santo Daime se reza mucho el Padre Nuestro, Ave María, hay una importancia a muchos santos de la religión católica, tiene mucho en común lo que pasa con diferencias importantes. Más que nada con la incorporación del Santo Daime. Principalmente la incorporación de la bebida, del Santo Daime, como un sacramento que se da como un sacramento casi como si fuera la hostia. El usar la bebida ya abre otras perspectivas, abre la mente, el espíritu, hacia otras cosas.

A juventude de Ernesto marca uma ruptura importante na sua vida. Morando num bairro residencial altamente conceituado de Montevidéu, assistindo a uma instituição particular de ensino médio, cujo perfil de estudantes é fortemente elitizado, as ânsias de "algo distinto" levaram Ernesto a deixar aquele contexto de conforto.

Yo llegué [ao Santo Daime] porque, no sé, a fines de la adolescencia, épocas de entrar a la universidad, tenía muchas inquietudes existenciales, para explicarlo de alguna forma. No sé, afán de conocer, como de descubrir alguna verdad que trascendiese la vida cotidiana, lo que se venía por delante, aquello de estudiar y recibirse, como que tenía una sed de algo distinto. Una intuición de que existía otra fuerza más allá de la que uno ve a simple vista.

Después que hice catequesis, la comunión y todo, al poco tiempo fui medio dejando de ir a las misas, a la iglesia y yendo poco. $Y$ en la adolescencia medio olvidado, no muy presente lo que fue la religión ni nada, y tá, hacia fines de la adolescencia, la juventud, más por el lado de una búsqueda, más bien influenciado incluso por lecturas como esto de Castaneda, de Don Juan y... cosas que uno leía que realmente cuando empecé en esa búsqueda ni me imaginaba que iba a terminar... que iba a encontrar lo que buscaba en una religión cristiana, ¿no?, como volviendo, volviendo al origen de estar rezando un Padre Nuestro, un Ave María.

Hoje em dia ele lembra colegas daquele contexto do colégio - inclusive alguns chegaram a participar de algum encontro na igreja -, mas Ernesto se 
distanciou bastante daquele núcleo de pessoas. Algum tempo depois, pôde recorrer àqueles colegas para trocar informações, pois vários deles escolheram desempenhar profissóes liberais, como o advogado ao qual Ernesto tem pedido conselho.

Con veinte años me fui a Brasil, este...realmente como que suspendí acá lo que estaba estudiando y una actividad que tenía de trabajo y todo... y... como que era muy fuerte en mí en ese momento salir al mundo a buscar, a conocer, este, incluso emprendí un viaje que pensaba hasta llegar a México y buscar a Don Juan el de Castaneda, entonces arranqué en esa, pero resolví hacer una escala en Río que yo siempre tenía muchos contactos en Río, tenía familiares, hermanos que ellos vivían ahí, primos, tíos, y, tá, hice una parada ahí y ahí en Río de Janeiro conocí un hermano mío que ya vivía ahí y estaba frecuentando la iglesia del Santo Daime, y, tá, ya cuando me contó, me sonó que eso tenía que ver con lo que yo estaba buscando y tal cual, la verdad que desde la primera vez que fui no... no he parado de ir hasta hoy, y eso ya hace... en el año 1988, o sea, hace 22 años.

Yo tenía 20 años, empecé a ir asiduamente, me hice miembro de la Iglesia y me fui a vivir a la comunidad que había en Río de Janeiro y yo me quedé 10 años viviendo en Brasil, en comunidad en RJ, y después me fui a vivir a la comunidad en el Amazonas. Y recién en el '96, ya una vez antes, una vez unos años antes que vine de visita, traje un poquito y, con dos amigos míos de otros tiempos, hicimos una pequeña sesión que, bueno, fue como una semillita y después sí...

Outros tempos ficaram atrás, pois o Daime produz mudanças radicais que levam a criar laços muito fortes entre os fiéis e dar início a "outros tempos", ao tempo transitando pelo Daime. Eis que, como o próprio Ernesto disse alguma vez, "uma vez que se vê, não se pode fazer como se não se houvesse visto".

$\mathrm{Al}$ principio me llamó mucho la atención que yo no imaginaba que fuera algo tan cristiano, tan religioso, que pasaba tanto por el lado de rezar y cantar himnos que hablan de Dios, que hablan de los santos, de llevar una vida más ordenada, 
por decirlo de alguna manera, y, bueno, pero yo, no sé, algo me tocó desde el principio, desde las primeras veces ya sentí que había respuestas ahí para mí, para las inquietudes que yo tenía. Digo, al principio fue un mundo nuevo, porque es un mundo el Santo Daime, es un pueblo, una cultura en su origen así en el Amazonas, ¿̨no? Realmente el povo del Santo Daime, como dicen los brasileros, que, tá, que yo cuando conocí me encanté y quise ser parte de eso.

Hubo un llamado, vi. Los primeros tiempos hubo cosas que realmente me atrajeron, que me sentí llamado con un gran deseo de hacer cualquier esfuerzo para formar parte de eso, como que vi un poder superior, vi la presencia de Dios en eso, en esa religión, en ese grupo, en lo que se practicaba ahí.

$\mathrm{O}$ jovem que transitara ambientes de elite fugiu daquele conforto para "sair a buscar", e o resultado dessa busca começou e terminou no Brasil, convertendo o desencantado e ainda esperançado Ernesto num dirigente religioso.

La primera vez que fui fue tranquilo, no fue una cosa ni muy fuerte ni nada, no más que en la sesión, cuando cantamos, que se cantaba, el himnario que se cantaba, en un momento tuve como un vislumbre de algo muy mágico que estaba ocurriendo, como que lo que estábamos cantando ahí estaba sucediendo al mismo tiempo, ya no te puedo explicar qué fue, ni qué fue, pero hubo un momento así realmente mágico que me enganchó y... acá hay algo más, hay algo más que es difícil comprender, y, bueno, y así entonces volví a ir. Quedé esperando cuando sería la próxima oportunidad y la segunda vez ya fue una visión importante de sentir realmente la presencia de Dios en todo, en el aire, penetrando a todo. A todos nosotros, a toda la humanidad a través del propio aire. Como que... fue una sensación muy fuerte de que Dios está en el aire, que entra en nosotros así. Y, bueno, uno lo dice así, pero en aquel momento todo eran vivencias fuertes importantes para mí. Y, bueno, ahí me empecé a arrimar mucho, a participar mucho, a ir casi todos los días a ver si había alguna actividad, si había alguna oración o si había actividad de trabajo que se pudiera participar, ayudar. Me fui integrando y volviendo parte muy rápidamente. Además, el sentimiento que yo tenía era que acá [Uruguay] había dejado todo para ir a buscar, entonces, mucho más rápido de lo que yo imaginaba, encontré. Y, sí, fue fuerte. Y, bueno, al principio la sensación 
fue como "ah, tá, ¿querías buscar? Bueno, acá está. Ahora es que empieza lo bravo, ahora empieza la parte dura."

E a igreja constituiu-se junto a Ernesto como seu dirigente. $\mathrm{O}$ jovem que "saiu a buscar" ficou em outros tempos, construídos no presente de um líder de uma comunidade religiosa que agora tinha outros desafios como...

\section{PERTENCER À IGREJA DO SANTO DAIME}

A igreja uruguaia do Santo Daime, Céu de Luz, pertence doutrinária e institucionalmente ao que foi fundado, em 1974, como CEFLURIS (Centro Eclético da Fluente Luz Universal Raimundo Irineu Serra). A linha fundada pelo Padrinho Sebastião Mota de Melo seria refundada em 1988, constituindo a vila Céu do Mapiá (no estado do Amazonas), a sede nacional. Uma década depois, a partir do IX Encontro das Igrejas em 1997, foi estabelecido o princípio de separação entre as instâncias espiritual/religiosa e a financeira/administrativa, dando origem, em 1998, à Igreja do Culto Eclético da Fluente Luz Universal (ICEFLU). ICEFLU é o novo nome da continuidade institucional, rede das igrejas daimistas, agora estatutária e especificamente ligada a questôes de ordem doutrinária. Por outro lado, o CEFLURIS (agora ocupado basicamente da administração e distrubuição de Santo Daime) passou a ser o Instituto de Desenvolvimento Ambiental (IDA-CEFLURIS). Dizíamos, então, que a igreja Céu de Luz, de Montevidéu, pertence a ambas instituições. Por um lado, doutrinariamente, Céu de Luz segue o calendário oficial, normas de ritual e demais preceitos estabelecidos pela tradição religiosa que vai do Mestre Raimundo Irineu Serra, passando pelo Padrinho Sebastião Mota de Melo, até o mais recente rearranjo institucional, ICEFLU, sob a atual presidência do Padrinho Alfredo Gregório de Melo, filho de Sebastião. A expansão e afirmação da doutrina dependem, em grande medida, das permanentes visitas que autoridades religiosas como Madrinhas e Padrinhos realizam às diferentes igrejas membro, dentro e fora do Brasil. Céu de Luz tem recebido várias dessas visitas. A atual máxima autoridade religiosa, Padrinho Alfredo, como já dissemos, visitou Céu de 
Luz em Montevidéu em duas oportunidades, sendo a primeira no ano 2000 e a última em 2006. Se a continuidade e consolidação da doutrina, criada pelo Mestre Irineu, teve em Sebastião Mota um momento importante com a fundação do CEFLURIS e de Céu do Mapiá, teve, a partir da presidência do Padrinho Alfredo, iniciada em 1990, seu momento de maior crescimento fora do Brasil. A ele é atribuída grande responsabilidade no processo de transnacionalização do Santo Daime, sendo uma pessoa que viaja muito, tanto no Brasil quanto no resto da América Latina, Europa e nos Estados Unidos. O calendário oficial dos trabalhos estabelece que o hinário do Padrinho Alfredo é cantado por ocasião do dia de São José (18 de março), de São Pedro (28 de junho) e da passagem de ano (31 de dezembro).

Uma Madrinha com a qual Céu de Luz tem afinidade é Maria Brilhante, que também visitou a igreja em Montevidéu, em 2002, 2009 e, recentemente, em 2012. Para Noé e Virginia, casal de jovens daimistas de Céu de Luz, a visita de Maria Brilhante em 2009 teve um valor particular, posto que ela participou do batizado da filha deles, Maia. Segundo o calendário oficial, o hinário de Maria Brilhante é cantado no dia de Santo Antônio, 13 de junho. Outra presença muito lembrada é a da Madrinha Júlia, que visitou Céu de Luz em 2007, quando os daimistas celebraram cantando o seu hinário. Segundo o calendário oficial, o hinário da Madrinha Julia é cantado no Dia das Mães, o segundo domingo de maio. Céu de Luz também recebeu outras visitas "oficiais", como as de Francisco Chico Corrente, duas vezes, e as de Daniel Serra, sobrinho do Mestre Irineu.

A pertença institucional à Igreja do Santo Daime e o estabelecimento desses laços com a matriz Céu do Mapiá possibilitaram essa série de intercâmbios e visitas das autoridades religiosas que moram na vila do Amazonas e consolidam a doutrina. Isso não significa que a organização das visitas, dos pagamentos, das hospedagens e agendas sejam fáceis. Algumas saídas desses Padrinhos ou Madrinhas pelas igrejas do Brasil e da região levam meses de viagens e estadia fora de Céu do Mapiá, o que implica, além da fadiga, custos importantes para as igrejas locais.

Mas a vida da igreja e do "povo" daimista não é feita só de visitas ilustres e amadurecimento espiritual. Aspectos burocráticos, políticos, de 
organização, principalmente no que refere à distribuição e administração do sacramento, criam disputas, aborrecimentos, idas e vindas que acabam produzindo, por exemplo, saídas institucionais.

\section{PARCERIAS E DESCONFORTOS; OU OS LIMITES DA FÉ}

Uma relação forte estabeleceu-se desde o ano 2000 entre as igrejas Céu de Luz de Montevidéu e CHAVE de São Pedro, em Porto Alegre. A primeira é comandada por Ernesto e a segunda, por Wilton, que, como vimos, conheceram-se na igreja Céu de São Miguel (RS), em 2000, por ocasião da visita do Padrinho Alfredo. A partir daí, constituiu-se uma relação de amizade que transcende questôes de ordem mais estritamente institucional. Os elogios recíprocos entre Ernesto e Wilton, as várias visitas que têm realizado, tanto entre eles (dirigentes) quanto entre outros membros das igrejas, evidenciam uma relação de parceria e troca entre duas igrejas que, não obstante a isso, têm transitado processos inversos nos últimos anos em relação à sua pertença institucional.

Embora ambas as igrejas acompanhem doutrinariamente o calendário oficial, as normas de ritual etc., as vias administrativas não são as mesmas. Isso significa, principalmente, que os mecanismos de obtenção e administração do Santo Daime, do sacramento, não são iguais para ambas as igrejas, já que, nesse sentido, respondem a administrações diferentes. Também existem diferenças ou matizes em relação ao estilo, à egrégora característica de cada igreja.

A própria trajetória de Ernesto faz com que exista uma relação próxima entre a igreja uruguaia e o que ele mesmo vivenciou nos anos em que morou entre Céu do Mar, no Rio de Janeiro, e Céu do Mapiá, no Amazonas. A centralidade de Céu do Mapiá, o incipiente processo de legitimação e construção da institucionalidade da igreja uruguaia e a completa dependência de fornecimento de Santo Daime fizeram com que hoje Céu de Luz responda oficialmente ao CEFLURIS, doutrinaria e administrativamente. A pertença ao Instituto CEFLURIS determina uma série de normas ou procedimentos em relação ao fornecimento de Santo Daime, que não deixa de preocupar ou colocar dificuldades, tanto para Céu de Luz quanto para a igreja CHAVE 
de São Pedro. Poucos anos atrás, então, começavam a se desenvolver processos diferentes nessas duas igrejas em relação à sua pertença institucional, já que, enquanto Céu de Luz se dispunha a seguir os passos burocráticos de reconhecimento institucional por parte do CEFLURIS, o CHAVE de São Pedro desenvolvia uma saída do CEFLURIS por ter encontrado algumas diferenças, segundo Wilton não doutrinárias, mas sim administrativas.

Um elemento importante que coloca em desigualdade de condições as igrejas Céu de Luz e CHAVE de São Pedro diz respeito à autossustentabilidade na obtenção do Santo Daime. Assim, para o caso da igreja uruguaia, a dependência de fornecimento externo de Santo Daime é total, sendo que não têm sido desenvolvidas estratégias bem-sucedidas no cultivo das plantas e do feitio do sacramento. Por outra parte, a despeito de algumas informaçôes contraditórias, no CHAVE de São Pedro, é possível cultivar as duas plantas necessárias para o feitio do Santo Daime e, de fato, têm sido realizados vários feitios ao longo dos últimos anos.

O feitio representa um momento crucial no processo ritual daimista. Vários dias de trabalho dedicados à colheita dos cipós e das folhas necessárias, à limpeza e a toda uma série de procedimentos estritamente normatizados vão concluir na obtenção de muitos litros de sacramento, que será engarrafado e utilizado ao longo do ano. O cuidado nesses passos e o conhecimento de quem fica responsável do feitio vão determinar a qualidade dos trabalhos espirituais que se realizarão com a substância obtida. Nesse sentido, por exemplo, a experiência de Ernesto morando em Céu do Mapiá e a amizade que estabeleceu com José Gonçalves (conhecido feitor dentro da doutrina e, mais tarde, patrono da igreja Céu de Luz) fizeram dele um respeitado feitor de Santo Daime. Tanto é assim que, em várias oportunidades de feitios no CHAVE de São Pedro, Ernesto é convidado para trabalhar com eles no processo.

Por outra parte, o fato de uma igreja poder realizar o seu próprio feitio, além do estritamente doutrinário/espiritual, significa uma relativa independência (político-econômica) de outros centros que possam estabelecer relações diretamente comerciais com a produção de Santo Daime. Além disso, o fato de centralizar a produção e distribuição de Santo Daime ao mesmo tempo em que a doutrina não deixa de se espalhar territorialmente, 
dificulta os mecanismos de abastecimento e incrementa os custos. O sagrado também é determinado pelo mercado.

A total dependência de Céu de Luz em relação ao fornecimento de Santo Daime faz com que os comentários de Ernesto sejam reservados nesse ponto. Por outro lado, a coragem de Wilton (que ele mesmo se atribui pelo fato de ter saído do CEFLURIS) possibilita uma maior exposição nos seus depoimentos. Segundo ele, um dos fatos que determinou o processo de saída foi um episódio que envolvia a construção de uma casa de feitio. Wilton tem narrado algum episódio no qual teria que ser construído um local para realizar os feitios na igreja Céu de São Miguel. No processo, ele teria encontrado diferenças em relação aos custos que exigia a dita construção. Para mostrar que aquilo que estava sendo solicitado para a construção era muito, construíram, no CHAVE de São Pedro, um local para feitios por um valor muito menor daquele que estava sendo feito em Céu de São Miguel. Essas diferenças com CEFLURIS foram, segundo ele, motivo de saída dessa instituição.

Se o feitio marca um momento de destacado valor simbólico dentro da doutrina, o "bom feitor" é possuidor de um conhecimento capitalizável em forma de distinção. Embora Ernesto não faça de sua experiência como feitor junto a José Gonçalves, no Céu do Mapiá, um elemento de distinção permanente, utiliza com discrição seu principal capital legitimador.

As formas escolhidas para narrarem suas próprias trajetórias (tanto por Ernesto quanto por Wilton), bem como os estilos de condução dos trabalhos, conduzem-nos a identificar atitudes de direção diferenciadas e, portanto, tomadas de decisões também diferentes. As escolhas que o CHAVE de São Pedro foi realizando em relação ao posicionamento institucional fazem sentido se olhadas sob a perspectiva da ênfase colocada pelo seu fundador e dirigente em se apresentar como um administrador, função na qual a agilidade executiva ocupa um primeiro plano.

A direção do CHAVE de São Pedro tem desenvolvido estratégias administrativas legitimadoras que necessitam cooptar os recursos disponíveis tendentes à autonomia. Wilton tem sido - e é - uma pessoa que sabe identificar as necessidades ou carências de uma determinada situação 
e colocar todo seu capital à disposição, a fim de potencializar essa falta e fazer dela um elemento de distinção. Por exemplo, a escolha do lugar onde está localizada a igreja responde, segundo ele, à necessidade de ter um lugar de encontro mais perto da cidade, que facilitasse o acesso à igreja por parte de maior quantidade de pessoas, ao mesmo tempo em que possibilitasse a manutenção de um ambiente propício para o encontro com a natureza e de um espaço que permitisse, entre outras coisas, realizar os seus próprios feitios.

No caso do processo uruguaio, algumas coisas são diferentes. A busca de "algo a mais" narrada por Ernesto, a saída do Uruguai e o retiro no mundo no qual estava se formando um profundo conhecedor da doutrina, configuraram uma narrativa muito eficaz, conforme a qual o retirante do mundo teria voltado com o conhecimento adquirido, acompanhado do seu mestre, criando um universo simbólico que fez sentido, rapidamente, entre aqueles que estavam conhecendo a novidade do Santo Daime no Uruguai. Seja no Céu do Mar, do Rio de Janeiro, no Céu do Mapiá, no Amazonas, ou no Céu do Patriarca, em Florianópolis, os primeiros uruguaios a conhecerem o Santo Daime tiveram que sair do país para ter acesso a um novo mundo que se abria à sua frente. Essas descobertas poderiam se ressemantizar no Uruguai, mais tarde.

Nos primeiros anos da década de 1990, em que expressōes religiosas, terapêuticas, em torno do uso da ayahuasca estavam chegando ao Uruguai, elas eram elementos desconhecidos, "vindos de fora", que começavam a construir suas redes em novos contextos. Nesse momento, no Brasil, a questão dos usos da ayahuasca já tinha sido colocada em debate, no âmbito nacional, em relação aos mecanismos de regulação do uso da substância ${ }^{8}$.

No Uruguai, estavam sendo criadas novas relações que impunham as estratégias de consolidação e ressemantização no novo local - poderíamos dizer - mecanismos "internos" ao grupo que iam se constituindo. Por outro lado, um novo Estado-nação estava incorporando, através de alguns membros da população, um conjunto de práticas desconhecidas, novas, sem contarem com antecedentes nem com uma tradição que pudesse dialogar

${ }^{8}$ Para uma síntese dos processos de regulação da ayahuasca no Brasil e Uruguai, ver (Scuro, 2012). 
com aquele universo simbólico, a não ser o "contorno" explicitamente cristão. O outro universo de sentidos do qual bebe a cosmologia daimista, um mundo indígena amazônico, chegava (pela mão do cristianismo) a "um país sem índios" (Basini, 2003).

\section{DESDOBRAMENTOS DO SANTO DAIME NO URUGUAI}

Como seria, então, uma igreja do Santo Daime no Uruguai? Stella, a mãe de Ernesto, não tinha muita fé quando soube dos planos do filho de inaugurar uma igreja do Santo Daime no Uruguai. Stella simplesmente não imaginava que uma igreja assim pudesse funcionar em seu país.

É que o Uruguai parece produzir uma autorrepresentação (e seria "visto" de "fora" sobre essa mesma ótica) de um modelo de laicidade e uma especificidade no processo de secularização (Caetano; Geymonat, 1997; Guigou, 2000) que, desde o final do século XIX e início do XX "dificultara" um processo de visibilização do religioso na esfera pública. A "falta de fé" de Stella na possibilidade de existir uma igreja como o Santo Daime no Uruguai evidencia essa imagem do Uruguai como um lugar onde seria difícil o andamento de uma pluralidade religiosa.

No entanto, o modelo de laicismo radical que caracterizou o Uruguai da segunda metade do século XIX e primeiras décadas do XX (Caetano; Geymonat, 1997) parece estar sofrendo certas mutações nos últimos vinte e cinco anos, no mínimo. Assim o evidenciam os aportes locais dos últimos tempos, preocupados em observar as mudanças no interior do campo religioso uruguaio e o lugar que as diferentes manifestaçóes religiosas ocupam no espaço social da nação (Da Costa, 2004;, 2008; Geymonat, 2004; Guigou, 2006; 2008; Pi Hugarte, 1993; 1998; 1999), sendo que parte significativa deste processo está relacionada ao estudado fluxo religioso entre Rio Grande do Sul e Uruguai (Oro, 1999).

Voltando a Stella: vários anos depois, ela afirma ser um sucesso total o fato de a igreja contar com umas cinquenta pessoas que têm se mantido firmes durante tanto tempo, "poucos, mas bons". Stella é uma mulher com 
muita vida vivida, entre ideais, filhos, diferentes territórios, comunidades, línguas (ela é tradutora), experiências, enfim, que fazem dela uma mulher que se apresenta com calma, sabedoria e tenacidade. Morou por uns trinta anos no México, para onde disse ter sido uma das primeiras pessoas a levar o Santo Daime, embora as religiōes indígenas e o uso de "plantas de poder" sejam objeto, segundo Stella, de muito preconceito e dificuldades no México. Stella entende que, nesse sentido, as políticas uruguaias sempre têm sido mais liberais em relação ao tema "drogas".

Ela se fardou na mesma igreja daimista que Ernesto, a Céu do Mar, no Rio de Janeiro. Dessa comunidade daimista também participava outro filho dela, Claudio, que Ernesto conheceu quando chegou lá em 1988. Também morou um tempo no Céu do Mapiá, embora ela e Ernesto nunca tenham convivido na vila da floresta. As lembranças de Stella sobre os trabalhos feitos no Mapiá levam ela ao encontro com uma energia que entende não ser possível ter fora daquele contexto. O fato de participar de um trabalho em Mapiá, na presença do Padrinho Alfredo, não tem, segundo Stella, ponto de comparação com nada. No entanto, embora a força da floresta não esteja presente nas igrejas localizadas fora do Amazonas, a presença de determinadas visitas fazem com que as experiências nessas igrejas sejam muito fortes, "incríveis", diria Stella. Foi o que aconteceu quando o próprio Padrinho Alfredo visitou Céu de Luz, em Montevidéu, em 2000 e 2006, por exemplo.

A mesma "perda" de força que fala Stella é mencionada por Alejandra em alguns depoimentos quando se refere às religiōes afro-brasileiras. A irmã e o cunhado de Alejandra faziam parte do grupo de pessoas que participou daqueles primeiros trabalhos dos inícios da igreja Céu de Luz. Pouco tempo depois, Alejandra começou a participar da vida da igreja e se fardou.

Segundo Alejandra (que também morou em Céu do Mapiá), as religiōes afro-brasileiras, quando chegam ao Uruguai, perdem o sentido e já não são a mesma coisa. Sua postura em relação ao tema nos faz pensar em dois questionamentos simultâneos: um primeiro em relação à legitimidade das religiōes afro-brasileiras presentes no Uruguai; e um segundo relativo à própria legitimidade do Santo Daime nesse mesmo país, pois o Santo Daime 
é, também, uma religião de origem brasileira no Uruguai. Nas conversas que tivemos com Alejandra, Ernesto e Stella sobre os processos ou as adaptações que as religiōes vão sofrendo, eles iam assumindo posições diferentes.

Por exemplo, Ernesto não acha que o fato de uma religião sair do Brasil e chegar no Uruguai faça com que ela perca o sentido, pois isso mesmo poderia estar acontecendo com eles. Em vez disso, Ernesto entende que é necessário um processo de adaptação à localidade, uma "uruguaização" do próprio Santo Daime. A partir dessa postura, a relação com as religiōes afro-brasileiras

${ }^{9}$ Sobre o tema das adaptações que os diferentes segmentos sofrem ao passar, por exemplo, a território uruguaio, Oro (1999) abre uma discussão interessante que encontra nas posiçóes de Pi Hugarte um certo extremo. Afirma o antropólogo uruguaio: "Es sabido que jamás un rasgo cultural procedente de una cultura ingresa a otra sin sufrir redefiniciones que lo alteran de acuerdo con las pautas de la cultura receptora. Valga este principio general para señalar que la umbanda del Uruguay no es del todo idéntica a la umbanda del Brasil y que tampoco el batuque portoalegrense es aquí exactamente lo que es en su lugar de origen. Las adaptaciones se notan en los contenidos mítico-ideológicos y en las manifestaciones litúrgicas de todos los cultos y puede preverse que en los tiempos venideros se asistirá a la aparición de formas uruguayas propias de los mismos, aunque no alcancen a desdibujar su naturaleza original" (Pi Hugarte, 1993, p. 130). Já Oro afirma: "pessoalmente, sugiro que as religiōes afro-brasileiras ao mesmo tempo em que reproduzem nos países do Prata, e alhures, uma capacidade de adaptação territorial historicamente demonstrada, preservam seu ethos e mantém uma imagem de África e de Brasil" (Oro, 1999, p. 55).

Como evidenciam as citações acima, a postura de Pi Hugarte parece, em princípio, um tanto quanto mais "radical" em relação à especificidade de formas locais que possam se desenvolver. Oro insiste na permanência de imagens da territorialidade "original". As duas posturas delatam o problema central ao que nos referimos ao tentarmos observar processos de transnacionalização religiosa (ou de qualquer outra coisa). Longe de pretendermos acabar com o debate, vemos que ambas as posturas ratificam o lugar central do Estado-nação enquanto matriz produtora de singularidades. A postura de Oro, porém, possibilita a entrada de imagens de "fora" desses Estados-naçōes, introduzindo, por exemplo, o elemento "África". Talvez devêssemos tomar essa "imagem" para pensar o significado que "Amazônia" tem no mundo daimista.

Prefiro pensar que ambas as posturas não são excludentes uma da outra, mas que, pelo contrário, estão mutuamente implicadas no permanente processo de repetição e mudança de imagens anteriores, sempre resultados de transnacionalizações e ressignificaçóes previas.

Para uma leitura sobre os sentidos elaborados em torno da ayahuasca em contexto europeu, ver (Groisman, 2000, 2009; Losonczy; Mesturini, 2010). 
muda de sentido, já que ela implica vislumbrar não necessariamente todos os praticantes desse segmento como representantes ilegítimos.

O segmento afro-brasileiro representaria um possível alvo de disputa simbólica por parte do Santo Daime, fora, é claro, as próprias lógicas do campo ayahuasqueiro. Expressōes religiosas (principalmente provenientes do Brasil) começaram a fazer sentido no Uruguai, criando uma paisagem de formas de crer diferentes. Com efeito, surgiram outras vias de chegada do fenômeno religioso, diferentes dos tradicionais mecanismos produzidos tanto por eventos de conquista quanto por contingentes migratórios.

Para alguns daimistas, comemorações das religiões afro-brasileiras-uruguaias ${ }^{10}$, como a de Iemanjá, no dia 2 de fevereiro, na Praia Ramírez (Montevidéu), não passam de um espetáculo. No entanto, elementos provenientes daquele âmbito do religioso, como a figura de Iemanjá, são incorporados no calendário ritual da Igreja Céu de Luz, cujos seguidores celebram a deusa dos mares no dia 2 de fevereiro. Alguns membros de Céu de Luz manifestaram seu interesse em conhecer mais sobre a religiosidade afro-brasileira, mas os praticantes desse segmento não são, necessariamente, para esses daimistas, representantes legítimos de linhas espirituais confiáveis. A possibilidade de algumas expressōes afro-brasileiras-uruguaias não trabalharem "na luz" (utilizando, por exemplo, mecanismos mágicos que pretenderiam beneficiar algumas pessoas prejudicando outras) não é bem vista por alguns daimistas.

Dando forma à ideia de um centro eclético, no interior das práticas daimistas, produzem-se outras imbricaçôes. Guillermo, jovem fardado de Céu de Luz, vem desenvolvendo há algum tempo, a capacidade da incorporação espiritual:

A mí lo que me pasa cuando me baja, lo que me pasa a mí, yo estoy ahí y, de repente, siento una electricidad que me sube por la columna vertebral, me pega acá y ahí empieza a acontecer todo aquello y yo sé, porque ya le he

\footnotetext{
${ }^{10}$ Refiro-me às religiões de origem africana, reterritorializadas no Brasil e, ultimamente, presentes no território uruguaio. $\mathrm{O}$ emprego do termo não pretende ser um argumento no sentido do debate expressado na nota anterior.
} 
preguntado, que es un caboclo boiadeiro que se llama João José Boiadeiro y es de la sierra de Aceguá (Guillermo).

Muitos membros de Céu de Luz tiveram, ou têm, algum tipo de contato com o Brasil, seja viajando nas férias, morando em diferentes lugares, ou conhecendo pessoas deste país. Guillermo não é a exceção. Nesses seus cinco anos de fardado, viajou a Florianópolis (também a Porto Alegre) pelo menos em três oportunidades. A primeira dessas viagens ocorreu depois de dois anos de fardado. Ele foi participar de um feitio na ilha, na comunidade daimista Céu do Patriarca. Ali conheceu Simone, quem, na seguinte visita de Guillermo ao Brasil, voltaria com ele para o Uruguai. Pedro, o filho deles, tem pouco mais de um ano. Naquela ida a Florianópolis, Guillermo viajou junto com Noé, outro jovem fardado de Céu de Luz. No dia em que Guillermo se fardaria, Virginia, sua irmã, participou do trabalho; foi o seu primeiro trabalho. Pouco tempo depois, Virginia e Noé se casaram na igreja. Hoje têm uma filha chamada Maia, de três anos de idade, batizada em Céu de Luz.

Voltemos a Guillermo e seu processo de aprendizado com a incorporação do caboclo João José Boiadeiro. A formação como ator de Guillermo ajuda o seu corpo (embora não determine) à possibilidade de alojar uma entidade que utiliza esse meio material para se manifestar. Embora ele não veja uma relação direta entre o fato de ser ator e desenvolver a capacidade da incorporação, reconhece uma facilidade que seu corpo tem para se soltar ao desempenho de um papel, para incorporar um personagem que utiliza o seu corpo como via de expressão. Isso acontece com João José Boiadeiro, um caboclo que trabalha, segundo Guillermo, com energias muito pesadas pelas próprias características de suas funçóes como encarregado de conduzir a boiada. A figura do caboclo é vivenciada por Guillermo como a daquele gaucho que se aproximou de uma fazenda para trabalhar. João José Boiadeiro (o nome do caboclo) é falado por Guillermo em português, embora ele seja da serra de Aceguá, em território uruguaio.

E assim como João José Boiadeiro apresenta-se em língua portuguesa, sendo pensado como um gaucho da serra de Aceguá, outras relações são 
pensadas em torno da língua na qual são realizados os trabalhos. A doutrina do Santo Daime, todo o hinário oficial, é criada em língua portuguesa. Da comunidade daimista uruguaia, muitas pessoas, como dissemos, têm estabelecido algum tipo de relação com o Brasil e com a língua portuguesa, e inclusive muitos têm conhecido Céu do Mapiá. Para muitos dos que frequentam a igreja Céu de Luz, não representa um inconveniente que os hinos sejam cantados em língua portuguesa. De fato, como muitas vezes contou Wilton em relação aos trabalhos dos quais participou em Céu de Luz, neles os hinos são cantados "quase sem sotaque, perfeitos, às vezes... uma palavra".

Em relação aos hinos, então, não há problema nem discussão se devem ou não serem cantados em português. O fato deles terem sido "recebidos" em português também não se discute nem que eles constituem os ensinamentos da doutrina, feita em português. No entanto, a relação com outras oraçōes dos trabalhos, como o Pai-Nosso e a Ave-Maria, produz opiniōes desecontradas. Ernesto, que morou dez anos no Brasil e, segundo Wilton, "fala português perfeito", tem uma postura de abertura à discussão sobre a língua na qual devem ser rezados o Pai-Nosso e a Ave-Maria. Se, para Ernesto, poderia ser bom rezar essas orações em espanhol, para fazer com que todos tenham uma relação mais estreita com o que está sendo rezado e pelo fato de serem orações já conhecidas em espanhol, para Stella, não é bem assim. Stella entende que o Pai-Nosso deve ser rezado em português. Um argumento que ela coloca é o de que muitas pessoas fugiram já das tradicionais orações como o Pai-Nosso, conhecidas em espanhol. O fato de realizarem orações numa outra língua produz, segundo Stella, um novo atrativo, a possibilidade de se encontrar com outra coisa, embora, talvez, nem todo o mundo entenda tudo o que está sendo dito. Esse é um problema que pode dificultar os trabalhos, pois, nos hinos, algumas pessoas podem ter dificuldades para compreender alguma palavra. Inclusive, pode acontecer o que ocorreu no próprio caso de Stella: ela aprendeu o Pai-Nosso diretamente em português e afirma não conhecer a oração em espanhol, pois não teve uma educação católica pela qual pôde aprendê-la. Para ela, o Pai-Nosso, já tem um sentido em português. 


\section{PARA FINALIZAR}

Quais os liames de João José Boiadeiro, um caboclo-gaucho da "Sierra de Aceguá" que "baixa" (umbanda?) no corpo de um ator uruguaio daimista?

Mais do que responder a pergunta, o artigo tentou, como dissemos, mostrar como se desenvolveu o processo de fundação de uma nova instituição religiosa no Uruguai.

O que se transnacionaliza, entre outras coisas, são imagens, lembranças, narrativas, sentidos únicos, "individuais", que serão (ou não) socializados em um novo contexto, abrindo as possibilidades imaginárias do receptor. Mas a atribuição de sentido nunca é individual, pois a condição de sua existência é produto das interações em contextos de socialização produtores de imaginários.

\section{REFERÊNCIAS}

BASINI, José. Indios num país sem indios: a estética do desaparecimento. Um estudo sobre imagens índias e versões étnicas no Uruguai. Tese (Doutorado em Antropologia Social). Universidade Federal do Rio Grande do Sul. Porto Alegre, 2003.

CAETANO, Gerardo; GEYMONAT, Roger. La secularización uruguaya (1859-1919). Montevideo: Santillana, 1997.

CAPONE, Stefania. Religions «en migration»: De l'étude des migrations internacionales à l'approche transnationale. Autrepart v. 56, 2010. p. 235-259.

DA COSTA, Néstor. (Coord.). Guía de la diversidad religiosa de Montevideo. Montevideo: Santillana, 2008.

. Lo religioso en la sociedad uruguaya. In: GEYMONAT, Roger (Comp.). Las religiones en el Uruguay. Algunas aproximaciones. Montevideo: La Gotera, 2004. 
GEYMONAT, Roger (Comp.). Las religiones en el Uruguay. Algunas aproximaciones. Montevideo: La Gotera, 2004

GREGANICH, Jéssica. "Entre a rosa e o Beija-Flor": um Estudo Antropológico de trajetórias na União do Vegetal e no Santo Daime. Dissertação (Mestrado em Antropologia Social). Universidade Federal do Rio Grande do Sul. Porto Alegre, 2010.

GROISMAN, Alberto. Trajectories, Frontiers, and Reparations in the Expansion of Santo Daime to Europe. In: CSORDAS, Thomas (Ed.). Transnational Transcendence. Essays on religion and globalization. Berkeley: University California Press, 2009. p. 185-204

. Santo Daime in the Netherlands: An Anthropological Study of a New World Religion in a European Setting. Tese (Doutorado em Antropologia). University of London, 2000.

GUIGOU, Nicolás. Religiāo e Produção do Outro: mitologias, memórias e narrativas na construção identitária das correntes imigratórias Russas no Uruguai. Tese (Doutorado em Antropologia Social). Universidade Federal do Rio Grande do Sul. Porto Alegre, 2008.

. Religião e Política no Uruguai. In: ORO, Ari (Org.). Religião e Política no Cone Sul. São Paulo: Attar, 2006.

- A nação laica: religião civil e mito-práxis no Uruguai. Dissertação (Mestrado em Antropologia Social). PPGAS. Universidade Federal do Rio Grande do Sul, 2000.

LABATE, Beatriz. A reinvenção do uso da ayahuasca nos centros urbanos. Campinas: Mercado de Letras, 2004.

LOSONCZY, Anne-Marie; MESTURINI, Silvia. La selva viajera. Rutas del chamanismo ayahuasquero entre Europa y América. In: Religião e Sociedade, Rio de Janeiro. v. 30, n. 2, 2010. p. 164-183.

ORO, Ari. Axé Mercosul. As religiōes afro-brasileiras nos paises do prata. Petrópolis: Vozes, 1999. 
PI HUGARTE, Renzo. Transnacionalização da religião no cone-sul: o caso do Uruguai. In: ORO, Ari; STEIL, Carlos. Globalização e religiāo. Petrópolis: Vozes, 1999. p. 201-218. 1998.

. (Coord.). Los cultos de posesión en Uruguay. Montevideo. EBO,

- Permeabilidad y dinámica de las fronteras culturales: Umbanda y Pentecostalismo en el Uruguay. In: FONSECA, Claudia (Org.). Fonteiras da cultura. Horizaontes e territórios da antropologia na América Latina. Porto Alegre: UFRGS, 1993. p. 122-131.

SCURO, Juan. No Uruguai também há Santo Daime: etnografia de um processo de transnacionalização religiosa. Dissertação (Mestrado em Antropologia Social). Universidade Federal do Rio Grande do Sul. Porto Alegre, 2012. 